\title{
Chapter 13 \\ Conclusions and Future Lines of Inquiry in Mathematical Modelling Research in Education
}

\author{
Jill P. Brown and Toshikazu Ikeda
}

\begin{abstract}
This final chapter overviews the 12 contributions to the monograph, organising this along the lines of inquiry suggested by Stillman. Contributors share understanding of mathematical modelling as solving real-world problems. The value and purposes of implementing modelling varies, in part due to local curricula. Theoretical underpinnings of the research include prescriptive modelling, modelling cycles, and modelling competencies. The challenges of engaging in modelling see empirical foci on modellers, teachers, and tasks whilst acknowledging interactions between these. Other important areas of the field, where researchers need to focus in the future include research with experienced student modellers, research on experienced teachers of modelling, and successful mathematisation by modellers.
\end{abstract}

Keywords Modelling tasks - Teachers of modelling - Prescriptive modelling • Affordances

\subsection{Mathematical Modelling: What Lines of Inquiry?}

Defining the bounds of research reported in this monograph is important. This includes the shared understanding by authors as to what mathematical modelling is. Modelling occurs when teachers, students, mathematicians, and others attempt to describe some aspect of the real-world in mathematical terms in order to understand something better or take or recommend actions (e.g. Blum 2015; Blum et al. 2007). All authors in this volume view the real-world as important throughout engagement

\footnotetext{
J. P. Brown (凶)

Australian Catholic University, Room 1.52, Level 1, 250 Victoria Parade, Melbourne, VIC 3002, Australia

e-mail: jill.brown@acu.edu.au

T. Ikeda

College of Education, Yokohama National University, 79-2 Tokiwadai,

Hodogaya-ku, Yokohama, Kanagawa 240-8501, Japan

e-mail: toshi@ynu.ac.jp

(C) The Author(s) 2019 
in mathematical modelling, as the task solver is aware that any solution that does not make sense in the real-world is no solution at all. The real-world may take a back seat to the mathematical world at times, however, it is never entirely absent (e.g. Julie and Mudaly 2007).

Understanding how chapter authors define mathematical modelling in this book is clear. However, this is not always the case in research reporting, as articulated by Brown in her chapter discussing the multiple varied meanings of context, task context, and real-world task context-all critical to reading and doing research about mathematical modelling and applications. Brown's study was of research reported in general mathematics education research, however, even within the modelling community, we should not assume others have the same understanding or definitions as ourselves, or even assume there is only one interpretation of these. In other words, the mathematical modelling research community must be scholarly in both our work and the reporting of this.

The need for a shared understanding of modelling by authors extends to other key terms but it is impacted by the value placed on modelling and its place in various curricula around the world. The value of mathematical modelling and applications should be clear to all. An explicit articulation of this can be found in the statement by Blum et al. (2007) that "nearly all questions and problems in mathematics education, that is questions and problems concerning human learning and the teaching of mathematics, influence and are influenced by relations between mathematics and some aspects of the real world" [emphasis added] (p. xii). However, there is still much variation as to whether this importance is recognised by curriculum writers and included in school curricula, and, where included-if this is implemented by teachers.

In Germany, Maaß (2016) reports that mathematical modelling is part of the national standards of mathematics education. Hankeln, Adamek and Greefrath (this volume) note that the German national standards, include the expectation that students translate real situations to mathematical problems, solve the mathematical problem, and interpret and check the results in terms of the real-world situation. This has meant professional learning on various aspects of mathematical modelling is available and textbooks include some modelling tasks. Maaß notes that many teachers, but not necessarily the majority of teachers, include mathematical modelling as part of their teaching repertoire.

In contrast, the framework of the Japanese mathematics curriculum is based on pure mathematics. Mathematical modelling has been given some emphasis and it is more emphasized in the next curriculum to be introduced from 2020. Some teachers implement aspects of mathematical modelling in their daily classroom teaching. However, there are difficulties related to incorporating mathematical modelling into a curriculum based on pure mathematics (Ikeda 2015). Namely, it is not explicitly described in the national curriculum at which grade and with what content teachers might introduce mathematical modelling.

Blomh $ø$ j reports that in the Danish secondary school systems, modelling, whilst included in the curriculum, is not "really integrated, in the curriculum" in practice. Fulton et al. report that modelling is rarely part of the US primary school curriculum 
even though it has come into the high school curriculum. Caron's chapter considers the feasibility of introducing modelling into the school curriculum in Canada, so we can infer it is currently absent, or scant, in some Canadian states. Similarly, grade 11 students in the study by Ortega, Puig and Albarracín, had no previous experience with modelling, so we infer, modelling is either absent from the Spanish curriculum, or present but not implemented. Similarly, the study in Israel by Zubi, Peled, and Yarden was introducing primary students to modelling tasks, so we infer this is not the norm.

One reason for the limited focus on mathematical modelling may be due to its high cognitive demand (Stillman et al. 2009). This is the nature of mathematical modelling as students make sense of the messy real-world and simplify this in order to bring it into the mathematical world in a way that can be managed and solved. In addition, the complex nature of modelling often sees students working in groups. Collaborative group work can enhance opportunities for successful solution of a given task, however, students need to learn how to work in groups, and do so collaboratively. If this is not a normal classroom practice, then an additional challenge exists as students learn to work collaboratively during modelling.

On the one hand, there are issues related to the value of mathematical modelling and its place in curricula documents, and the challenges for students in working together to solve such tasks. On the other hand, there exist issues related to teachers, their belief that modelling is an important part of mathematics, and being prepared to implement modelling tasks with students and face the challenges involved. As with students, the distance between the usual classroom practices implemented by the teacher and those required when modelling, increases the level of challenge for the teacher. Blum (2015, p. 83) gives insight into this distance when he laments,

generally speaking, the well-known findings on quality mathematics teaching hold, of course, also for teaching mathematics in the context of relations to the real world. This seems selfevident but is ignored in classrooms around the world every day a million times.

Whilst this situation continues to be the case, the distance between the normal or usual classroom teaching and learning environment_-for both teacher and students—and that necessitated by engagement in mathematical modelling increases the challenge of implementation by the teacher and successful solving by students.

\subsubsection{Goal, or Purpose, of Mathematical Modelling}

The goal of implementing modelling varies across the studies reported. Consistent with all chapters in this monograph, Ortega et al. take the stance that all mathematical modelling involves translating from reality to the mathematical world and back, "where reality is taken to be the rest of the world other than the mathematical domain" (Ortega et al. 2019, p. 162). Caron focusses on the need to live in the real-world as she argues strongly that if curricula were organised around habits of mind students, future professionals, and citizens in general would be better prepared for life in today's 
complex world. By habits of mind, she follows Cuoco et al.'s (1996) construct of "being comfortable with ill-posed and fuzzy problems ... to look for and develop new ways of describing situations" (p. 373) and hence be more prepared to deal with decisions associated with problems in the world today.

Many have discussed the dual purposes of teaching "modelling as a vehicle" (Julie and Mudaly 2007, p. 503) to learn mathematics and modelling as content in its own right (e.g., Galbraith et al. 2010). Blomhøj argues that both are important and proposes ways to support teachers integrating modelling in secondary teaching practices. He noted teachers' difficulty was how to connect the students' modelling to understanding the mathematical knowledge in the curriculum. Czocher argues there has been an increased emphasis on mathematical modelling in curricula, and suggests the shift has been toward the modelling as content approach, although much emphasis is still on the former. Given that Julie (2002) noted "it is during the engagement with mathematical modelling as content that windows of opportunities are opened for dealing with relevance relevantly" (p. 8, emphasis added), this is a concern. Julie (2002) noted that teachers tend to prefer modelling as vehicle as the relevance to current teaching and learning mathematical content is more obvious. Sadly, development of learners as problem solvers and mathematical modellers seems less important. It appears teachers are still challenged in situations where different solution paths are followed by different students (Tan and Ang 2013). Teachers need to accept that real-world problems are likely to have multiple possible solutions and approaches to reaching these solutions (Blum 2015). Along these lines, Fulton et al. consider how communities of practice support teachers in being ready to respond to multiple student ideas.

Several authors focused on task development with Czocher noting that when this is part of a planned learning trajectory the task must have intended solutions which can be problematic when the intention is modelling as content. Ortega et al. took a modelling as vehicle approach with a teaching experiment focussed on learning about linear and quadratic functions. Whilst context was important, they found students tended to use prior knowledge when interpretation was required, rather than the functions they had found to mathematise the real phenomenon.

Caron describes multiple specific habits of mind students should be developing, including thinking of change analytically, thinking of systems in terms of flows, algorithmic and iterative ways of thinking, modelling interactions as inflows and outflows, and use of functions as building blocks for modelling. This is in contrast to modelling with functions via curve fitting and or regression which, she argues, along with Doerr et al. (2017) and Galbraith (2007), allow only a restricted understanding of the realworld situation being investigated. Brown (2015b) concurs noting "the enactment of multiple Data Display-ability simultaneously with multiple Function View-ability has the greatest potential in the model finding phase" (p. 437) and provides visual representations of both the data and model simultaneously, allowing modellers to keep the real and mathematical worlds at the forefront of their minds. The purpose of modelling, argues Caron, is not only to support students in understanding and integrating mathematical ideas but also "as a goal in itself of mathematics education" (Caron 2019, p. 83), that is, modelling as content. 
Mathematical modelling plays an important role within social-critical research of mathematics education as a result of the relationship to the real world. The sociocritical perspective accounts for all participants' situations and backgrounds and aims to position learners as independent decision makers and critical users of information. Araújo's goal for mathematical modelling in her chapter is quite different. She presents initial steps toward a framework based on the notion of a mutually dependent dialectic relationship between practice and research. Relationships might be between practice and research, researcher and teacher, or student and research participant. Such a framework is a valuable contribution to socio-critical research specifically and modelling research more generally.

\subsection{Theoretical Lines of Inquiry}

In the opening chapter, Stillman (2019) discusses four theoretical lines of inquiry. The three local lines of inquiry, that is, those particular to mathematical modelling, are prescriptive modelling, modelling frameworks or modelling cycles, and modelling competence. The general line of inquiry discussed is anticipatory metacognition. Further research involving all three local lines of inquiry arose in this book and are discussed here. Anticipatory metacognition was not part of research reported and will be discussed along with other future lines of inquiry in the concluding section of this chapter.

\subsubsection{Prescriptive Modelling}

Meyer (1984) clearly defines mathematical modelling, models and mathematical models, with mathematical modelling being "an attempt to describe some part of the real world in mathematical terms... an endeavour as old as antiquity but as modern as tomorrow's newspaper" (p. 1). Meyer (1984) writes of different types of models, "a descriptive model, which tells how something works, and a prescriptive model, which tells the ideal way for it to work" (p. 60). He notes that prescriptive models are also known as optimisation or normative models. The difference is related to the purpose of use. A prescriptive model "is a tool for human decision making" (p. 61) whilst a descriptive model describes what is going on, and often "can be turned into a prescriptive one" (p. 61).

The example Meyer (1984) uses involves the manager of a retail store selling 20 soccer balls each day needing to know: How frequently, and what number of balls should be ordered from the supply factory. The descriptive model is presented in terms of an algebraic representation of a yearly cost function, $C(x)$, with variables, $r$, the rate the soccer balls are sold per day, $s$, the storage cost (of as yet unsold balls), $k$, the ordering cost (e.g. time of staff involved in ordering process), and $x$, the number of soccer balls per order (assuming each order is for an identical number of soccer 


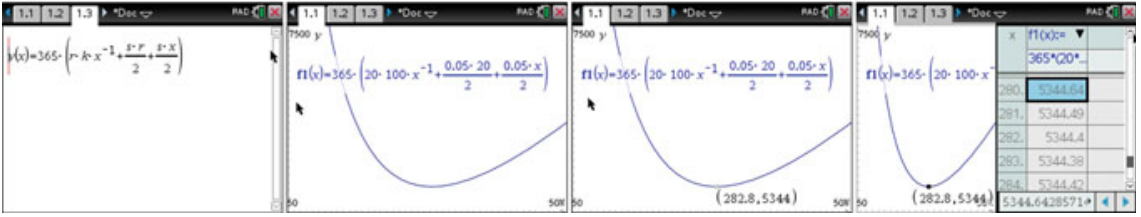

Fig. 13.1 a Descriptive model $\mathbf{b}$ specific model $\mathbf{c}$ mathematical 'best' $\mathbf{d}$ allowing actions

balls). The model can be used to find the cost per year for any combination of values of the variables. Thus, the model can be used to describe the yearly cost for any such situation (i.e. a descriptive model). In a given store, the first three variables may be assumed to be fixed hence a specific cost function can be found and represented, using several methods although a graphical representation should be the simplest. A visual inspection of the graph will show if the optimal value occurs at an endpoint of the domain or at a local turning point. The mathematical values then need to be interpreted as an integer number of balls and verified if that many can be both delivered and stored and thus is a solution to the real-world problem. The model is thus prescriptive as the task solver is expected to make recommendations as to what is best in terms of the number of soccer balls per order and frequency of orders. Figure 13.1 shows how digital technology can be used to (a) represent the general function or descriptive model, (b) find the algebraic and graphical representations of a situation given known parameter values, (c) find the mathematical best and (d) additionally use the graphical representation to begin to interpret what is best in the real world - this might include considering a range of possible values for the ball order, thus allowing other real-world considerations.

Davis (1991) argued we can distinguish at least three interrelated goals of applied mathematics, description, prediction, and prescription or "what $i s$, what will be, what therefore to $d o$ " (p. 6). He elaborates with descriptions related to planetary motion and population predictions. Prescriptions, he argues require actions such as acting to stop smoking given statistical evidence or prescribing the fuel tank volume for a plane designed to fly non-stop from Copenhagen to Singapore. Davis is clear on the intertwining of these goals for modelling and our need to attend to all. Niss (2015) has reminded us of the need for an increased emphasis on prescriptive modelling (see Chap. 1).

Several examples of these types of modelling with their related purposes of use appear in the chapters. The Yellowstone Game Task (Caron), Morning Shower and 100 metre Sprint (Blomhøj) involved descriptive modelling as the intention was to describe the situation or context under investigation. Similarly, the Water Usage Task used by Fulton et al., aimed to describe how much water is used in making a pizza is descriptive. Czocher's Letter Carrier task could be described as prescriptive as the aim was to determine the best route for the mail deliverer to follow. One task used by Zubi et al. with grade five students involved prescriptive modelling as the task involves recommending the best three volleyball teams using 15 players. Stender's 
Traffic Task required solvers to recommend whether to construct a roundabout or traffic lights at a given intersection and this is prescriptive.

Whilst no chapter authors referred specifically to descriptive versus prescriptive modelling, analysis of the tasks used and the purposes of their use in the research reported, shows both types were present and the majority, but not all, modelling tasks would be classified as involving descriptive models or descriptive modelling. This may be an artefact of the contexts investigated, the grade level of the modellers, the approach to modelling as vehicle more so than as content, limited previous modelling experience of the modellers, or a combination of these.

\subsubsection{Modelling Frameworks and Modelling Cycles}

Modelling cycles featured in the chapters of Blomhøj, Hankeln et al., Shahbari and Tabach, and Stender. These were used as an analytical tool by Shahbari and Tabach, and Blomh $\varnothing \mathrm{j}$ and as a structure for the research plan of Hankeln et al. and Stender. The modelling cycle acted as a structure for assessment tool development by Hankeln et al., in their research on modelling sub-competencies. Blomh $ø$ j reports that teachers use the modelling cycle as a tool for planning modelling activities. The modelling cycle was used as a structure for using heuristic strategies as strategic intervention in the study of Stender. Teachers in the study by Blomh $\varnothing j$ used the modelling cycle as a means to analyse student work.

As an analytical tool, Shahbari and Tabach mapped pre- and post-intervention teacher observation reports of students engaged in modelling to the modelling cycle of Blum and Leiß (2005). The intervention saw the teachers work on four modelling tasks themselves. Post-intervention, teachers were more observant of modelling activity. There was however, a large number of future teachers still at the lowest of three classification levels, that is, failing to describe the majority of modelling activity undertaken by student modellers. More attention was given by future and in-service teachers to the final modelling cycle, perhaps, initially underestimating its critical role in students getting to the final solution.

\subsubsection{Modelling Competence and Competencies}

Building on work in the field (e.g. Kaiser and Brand 2015), Hankeln et al. focus on modelling competence, described by Blomhøj and Højgaard Jensen as "someone's insightful readiness to act in response to the challenges of a given situation (2007, p. 47). Hankeln et al. note that whilst their focus is on the sub-competencies, simplifying, mathematising, interpreting, and validating (Maaß 2006), "their mere existence is not sufficient" (Hankeln et al. 2019, p. 145). The focus of Hankeln et al. was to determine if these sub-competencies can be measured as separate dimensions or not. 
Hankeln et al. present four sample tasks, one for each sub-competency, with a focus on geometric modelling. Analysis of each item is presented including selected incorrect responses and the success rate. Their research included 44 grade 9 classes and over 3000 completed tests. The thoroughness of this research is evident in the development and trialing of the items, compilation into test booklets, implementation and development of coding manuals for consistency of analysis. The findings by Hankeln et al. indicate that their statistical analysis shows it is possible to measure individual sub-competencies, at least with regards to geometric modelling situations relevant to grade 9 students.

\subsection{Empirical Lines of Inquiry}

In this section, following Stillman, lines of inquiry in the chapters that focus on the modeller, the task, and the teacher will be overviewed. Naturally, these are intertwined. A fourth and fifth line of inquiry, on the affordances of Technology-Rich Teaching and Learning Environments for modelling, and verification and validation concludes the section.

\subsubsection{Focus on the Modeller}

Fulton et al. note that in a country where modelling is rarely included in the primary school curriculum, teachers have an important role to play if modelling is to become integral to the mathematical learning of students. They recognise as challenging that primary mathematics teachers need support if modelling in primary schools is to become more widespread. Part of the support is of the teacher as modeller as Fulton at al. (and many others in the modelling community) opine that to teach modelling, one must first engage in modelling oneself.

\subsubsection{Impact of Modelling on Learning}

Zubi et al. focus on underachieving students in grade 5 in an Israeli school. They argue the role of the teacher, and expectations of students vary from classroom to classroom. In particular, in classes with perceived capable students, the expectation is on higher order thinking, but the converse is true in classrooms with low achieving students. Consequently Zubi et al. argue that low achievement is a result of the learning environment. Their study involved weekly modelling tasks, with the learning environment during the study contrasting with the norm. During the modelling sessions, students were expected to work in mixed ability groups on increasingly complex tasks. The chapter describes Sami, as typical of the low achieving students 
in this class, and his progress with regard to modelling competencies, mathematical knowledge, and participation in the group as they solved the tasks.

Teacher actions impacted on Sami's initial change of behaviour and motivation towards mathematics. Following the first task (where Sami decided to leave the mathematical work to more capable others), the teacher questioned the validity of the solutions. At this point, Sami, confidently and excitedly, shared that he had in fact proposed realistic considerations to his group but they ignored him. Subsequently all groups requested that they revisit their task solution. One can surmise, this was the first time Sami felt as if he had control over the direction of his own learning. Sami took an increasingly more active role in his group, from contributing realistic considerations, to actively organising his group, contributing mathematical ideas toward his group's model and finally to being dominant in organising his group, setting up a mathematical model and documenting the solution.

All low achieving students increased their mathematical knowledge of the content covered in the regular lessons during the study, whereas in a control class, taught by the same teacher, the low achieving students showed minimal development. The extended engagement of students with relevant real-world problems, that they were expected to solve in groups, and knowing that the solution was not predetermined by the teacher, allowed Sami and his peers, not only to develop modelling competencies and collaborative group work expertise, but also to view mathematics differently. It appears the expectations as to the role of the learner as modeller impacted on their engagement and motivation to learn in the regular classroom. Zubi et al. suggest that the introduction of, and student experience with, sustained modelling activity can also influence learning beyond modelling.

\subsubsection{Focus on Teachers of Modelling}

The teacher featured in the chapters by Caron, Czocher, Fulton et al., Ortega et al., Shahbari and Tabach, and Stender who all saw the teacher's role as critical. The focus included teacher knowledge about modelling (Fulton et al., Shahbari and Tabach), teacher knowledge of implementing modelling tasks (Fulton et al.), interactions between the teacher and modellers (Ortega et al., Stender) and expectations of teachers (Czocher).

Shahbari and Tabach recognised that teachers tend to lack knowledge about modelling, have limited experience in modelling, and teaching modelling. Similar to Zubi et al. and Fulton et al., the participants in the study of Shahbari and Tabach engaged in modelling activity themselves and undertook additional professional learning centred around watching and re-watching a video of a group of grade 6 students engaged in a modelling task. A second interaction with the video occurred after working on four modelling activities themselves. After each viewing of the video, the participants independently wrote a report of their observations. This activity enabled most teachers to become more alert to modelling occurring in student activity. 
Ortega et al. note the important role the teacher plays in supporting student engagement in, and reflection on, decisions related to technology use and mathematical modelling and the interactions between these. Stender also focuses on the role of the (future) teacher, with the intention of providing minimal intervention, or adaptive intervention for students during modelling. These interventions aimed at providing minimal help to maximise student learning and problem solving. Intervention levels include motivational support, strategic help, and content related strategic help and should be used in this order-from least to most support. In addition, six heuristic problem-solving strategies that can be used, differentially, when solving a particular modelling task were also considered as appropriate strategic interventions.

Stender found the strategic intervention of asking student modellers to "explain the work already done" (Stender 2019, p. 209) was very powerful as it was easy to implement, provided opportunity to diagnose students' immediate needs, and provided an opportunity for student modellers to reflect on progress. Teacher interventions for substantive modelling tasks should be prepared, rather than be in-the-moment according to Stender. To do this, teachers need to solve the task prior to task implementation to identify potential barriers during the task as well as possible strategic interventions.

Fulton et al. had primary teachers engage in a week-long intensive professional learning program, participating in the process of mathematical modelling and then, reflecting from the perspectives of a student learning to model and as a teacher, teaching others to model, the first feeding forward to the second. Four features of modelling were in focus: the openness at all stages of the modelling cycle and grappling with this idea as a norm; posing problems, not just solving someone else's problem and understanding that modelling begins with the real-world context rather than the real-world problem; making choices about what mathematics to use in solving the problem as posed; and looking back at various stages of the solution to revisit ideas and consider revising the solution. Professional learning included teachers developing a modelling task, anticipating potential solution approaches; implementing the task with their students; and finally revisiting the task. Fulton et al. found that teachers engaging with modelling tasks themselves, resulted in the development of mathematical communities of practice which were supportive of subsequent collaborative task development and implementation. Caron also argued that collaboration between teachers could be productive, although she was suggesting cross-discipline collaboration, for example between mathematics and science teachers to design real-world problems.

Fulton et al. found the teachers in their study responded to the view of modelling as real-world problem solving and worked together in communities of practice to develop and implement mathematical modelling tasks addressing problems that mattered to students. Relevance, engagement, and access (i.e. tasks allowing all learners to participate in the task solution) were present in tasks designed and implemented by the teachers. The teacher participants clearly saw the power of mathematical modelling, and correctly believed their students could use mathematics to successfully solve relevant real-world problems. Moreover, modelling was seen as providing opportunities to promote mathematical thinking, encourage perseverance, and increase student engagement with mathematics. Most importantly, the solution path 
followed by the teacher must be bracketed when the task is implemented (see Blum 2015). Blum and Borromeo Ferri (2009) refer to the "teacher's own favourite solution" (p. 53) and note that, all too often teachers, consciously or not, direct students toward this solution.

Drawing on empirical findings, Blum (2015, p. 83) sees individual solutions as an element for teaching and learning mathematical modelling and applications. Unpacking what Blum means by this, it is not-as may appear on the surface-that students work individually, nor favour the teacher solutions. Rather, Blum is arguing for the need for the teacher to actively encourage multiple solutions to any given task and that this be considered the norm by students.

\subsubsection{Focus on Modelling Task}

Focusing on task development, Czocher noted that any solution depends on particular assumptions. Different assumptions may lead to a different focus and/or a different solution method which may not be what the teacher intended. A critical aspect of mathematical modelling is, that the modeller makes decisions, for example, considering some, but not all real-world aspects in one's initial solution, describing how to interpret terms such as 'best'. Such mathematical thinking naturally leads to diverse solutions, but the task must be presented in such a way as to allow this.

Blomhøj also focused on task design as he worked with teachers and teacher educators to support mathematical modelling in Danish secondary schools. His intention was to allow modelling as both vehicle and content and the contexts used were very familiar to the task solvers. For the Yellowstone Game Task, Canadian educators and mathematicians worked on modelling a real-life ecosystem (Caron 2019). Groups worked together to try to represent the situations and or solve the problem as to why a recent significant increase in the bear population had occurred. This task was seen as important as multiple paths and multiple solutions could be, and were, found.

Fulton et al. determined four features wrestling with openness in modelling, posing problems, making choices through a creative process, and revisiting ideas and solutions (Fulton et al. 2019), as critical to modelling activity and hence task design. The first of these relates to the reality of the messy real-world and the need for modellers to grapple with this in order to make sense of the situation and determine a possible way forward. Problem posing relates to the expectation that teachers and students should pose modelling problems. Making choices focused on the modeller needing to decide the solution path and what mathematics might be needed, noting all too often the mathematics expected to be used in primary school is explicitly conveyed to the learners, whereas the making choices focus was more likely to generate multiple paths and solutions. The final feature highlights that a first solution may not be a real solution to the problem, so modellers should not consider the first answer as meaning, problem solved. 
Blomhøj presents two modelling situations suitable for secondary students. The Morning Shower Task sees students makes observations, collect data, and produce a poster communicating these. Digital technologies can be used to represent the data collected numerically and graphically to support communication of key ideas related to the mathematical function obtained and the real situation it represents. The emphasis of Blomh $\varnothing \mathrm{j}$ is certainly inclusive of the development of mathematical ideas (modelling as vehicle and as content). The $100 \mathrm{~m}$ Sprint Task saw students collecting data about a real-world situation and focused on understanding speed as the rate of change of distance over time. Digital technology use provided opportunities for multiple representations of the situation which could then be analysed and may lead to a deeper understanding of the mathematical concepts, or at least insight for students when these concepts are formally part of their mathematical learning.

Czocher used four tasks in her study of eight secondary school students and four university students, from several US states. Her tasks, the Letter Carrier Problem, the (human) Cell Problem, the Water Lilies Problem, and the Empire State Building Problem, ranged in degree of closeness to the real-world and level of complexity involved. Authenticity in Czocher's study, using actor-orientated theory, is based on the degree of alignment between task context and the task solver's lived experience. Consequently, task solvers are expected to use their own knowledge and make assumptions when solving a modelling task.

There was a strong emphasis on tasks allowing multiple pathways and solutions. Fulton et al. provided explicit criteria for task selection and design as appropriate to mathematical modelling. In contrast, Blomhøj saw any real-world context as providing opportunities to engage with both the real-world and the mathematical world, to develop understanding of both and the links between them. Czocher took an alternative approach as she tried to ascertain what solution was in the mind of the task setter and contrasted this with actual student solutions.

\subsubsection{Affordances of Technology-Rich Teaching and Learning Environments}

It is well known that digital technologies play an important role in mathematical modelling. Galbraith et al. (2007) described the "use of technology as central....and its integration with mathematics within the modelling process as creating essential challenges about which we need to know much more" (p. 130). This approach to digital technology use when modelling is taken up by Ortega et al. They acknowledge that use of digital technology to model provides opportunities to transform understanding. However, affordances of the environment including the technologies need to be perceived and acted upon (Brown 2015a) for this to occur.

Use of technology, its potential and ubiquitous nature should impact on the complexity of real-world contexts and modelling tasks explored by students of today. For several types of digital technology discussed, Caron highlights both the affordances 
and obstacles identified. By affordances she is following Gibson (1979) who made up the term to describe "the complementarity of the animal [i.e. the human] and the environment" (p. 127) and the definition used in Brown's research (2015a) on affordances in technology-rich teaching and learning environments as "the opportunity for interactivity between the user (the actor) and the technology (the object or the artefact) for some specific purpose" (p. 113) (see also Brown and Stillman 2014; Frejd and Ärlebäck 2017).

In the study reported by Ortega et al. the focus turns to capturing data using technological devices and identifying how decisions made by grade 11 students during mathematisation affect interpretation. Students in this study used multiple digital technologies. One class investigated the phenomenon of a bouncing ball using an iPad and an application allowing the motion to be video recorded and graphed after the user set the scale and origin of a coordinate system. The data collected (i.e. points on the image) are specified by the user. The data were exported to a second app allowing coordinate pairs to be plotted, regression analysis undertaken, and the subsequent function model graphed simultaneously with the data plot. With regard to the regression model, students were able to test multiple function types and ascertain which model best fitted the data.

A second class investigated the phenomenon of a spring's motion as marbles were added to a cup hanging from the spring. Again, video was captured using the iPad but then the data were exported to an app that did not perform regression analysis. In this class, students had to make additional decisions, regarding the type of function to use and subsequently to determine parameter values of that function. Post experiment, students in both classes used a graphing calculator app as desired to answer interpretation and validation questions. Galbraith (2007) would certainly see the use of technology in the second class as going "beyond the low hanging fruit" (p. 79) of "modelling as curve fitting" (p. 81) as students were expected to keep in mind the real world and its relationship to the mathematical model.

Students in the study by Ortega et al. did not perceive the affordances of the environment with regard to reference-point set-ability or understand the impact this has on the data collected, model determined and interpretation of that model and its outputs. However, given there is no evidence the students had previously used the technologies involved nor engaged in modelling, this is hardly surprising. Of course, the conception that a function's parameters are explicitly related to the location of the origin and scale factor of the imposed axial system critical in modelling is also an important aspect of pure mathematics that upper secondary students should be aware of.

Caron explored uses of system dynamics software (e.g. Stella) allowing the development of experimenting, tinkering, and qualitative analysis of problem situations such as the spread of viruses and social policies. Depending on the level of mathematics of the student modellers, Stella can be perceived as black box technology if the software uses mathematical analysis techniques, such as integration, not yet understood by the students. However, affordances here include experiment-ability and tinker-ability as student modellers with technology have the opportunity to develop 
or engage in these ways of mathematical thinking about complex situations. Both could be seen as part of what a mathematician might do before model generation.

Caron also explored cellular automata, that is a digital array of cells where the behaviour of an individual cell is determined by the cells surrounding it and their state in the previous generation. A local focus at the individual cell level over time allows insight into the global system behaviour. Such discrete models of dynamic systems can model situations including wildfires and spread of infections. The technology could involve a spreadsheet or online simulator. The affordances here are local behaviour predict-ability and global behaviour predict-ability with recursion being a key mathematical idea that could be introduced and understood as student modellers explore the way such systems evolve. Greefrath and Siller (2017) recommend "the uses of simulations that naturally link modelling with the use of digital tools" (p. 537). See also Frejd and Ärlebäck (2017) who used simulation to investigate a pandemic.

Agent-based models (e.g. NetLogo) are described by Caron as allowing modellers to investigate behaviour of an individual in a system and of the system itself. The behaviour of a nesting pelican and the colony it is a part of would be typical examples of this phenomenon. Predator-prey models can be utilised to ask and answer questions related to each of the necessary elements of the system. The affordances of such an environment allow modellers to engage in reasoning at the agent-based (individual-within-system behaviour reason-ability) and aggregate level (system behaviour reason-ability). The latter focusses on the rate of change of the populations within the system (Jacobson and Wilensky 2006).

There is no doubt the use of technologies in mathematical modelling results in higher order thinking needing to be undertaken by students with multiple decisions being made. From a modelling perspective, the more decisions made by students, the more mathematical thinking they engage in, and the greater their connection is to the real-world situation they are using mathematics to explore. As Ortega et al. conclude, students need more experiences in decision making in mathematical modelling and technology use and critically the interactions between these, as discussed previously by Galbraith et al. (2007).

\subsubsection{Verification and Validation}

Verification and validation are an area of modelling that needs to receive further empirical inquiry and attention (Czocher et al. 2018). In the study by Zubi et al. it was the teacher who initially questioned the validity of the students' solutions. None of the grade 5 student groups had taken the real-world into account as they proposed solutions to their first of a series of modelling tasks. This questioning by the teacher, and subsequent class discussion was the catalyst for change. From that point on, students increasingly valued the real-world as they searched for more authentic solutions. 
Model interpretation and validation were also a focus of Ortega et al. They found students had little experience in interpreting mathematics results in terms of reality (e.g. a negative height, or height of zero, predicted in the ball dropping experiment). In the spring experiment, students failed to notice, or account for the spring length changing. Ortega et al. found that rather than learning from observation of real data, students tended to revert to prior understandings even when these were inconsistent with their experimental activity (e.g. not setting the ground as a reference point but assuming this was the case when interpreting their model). In addition, students seemed not to be aware that the sign of a 'distance' is related to how and where it is measured. This resonates with the students in Czocher's study who, rather than make simplifying assumptions, maintained complexity of the situation under investigation. Both results suggest the need for increased student experiences with mathematical modelling and all the mathematical activity contained therein (e.g. simplifying, mathematising, interpreting, validating, verifying).

Caron also explored the idea that as solutions to real-world problems, and the mathematical techniques used to solve these, often involve approximations, both verification and validation are critical. Caron draws on the work of Roache (1998) to describe verification as ensuring "that the error has been controlled and that the equations have been solved correctly" (Caron 2019, p. 97) whereas validation relates to "external consistency, that is, ensuring the model and its associated solution adequately represent the situation". Caron argues that verification and validation are not typically part of mathematics teacher experience or expertise and this needs to be addressed.

Hankeln et al. in their research identify Validating as a modelling sub-competency. Their use of the term includes competencies for verifying a solution, critically reflecting on that solution and assumptions specified and the model selected. They argue this was the most difficult sub-competency to construct items to assess. The simplicity of these items belies the difficulty the researchers had in developing them but needs to be noted if using in teacher professional learning. Teachers in the study of Shahbari and Tabach gave the least amount of attention to validating processes when observing and interpreting students' modelling activity. These authors suggest this lack of attention to validating is, following Blum and Borromeo Ferri (2009), a result of this mathematical activity more typically being undertaken by the teacher in the normal classroom environment.

\subsection{Future Lines of Inquiry}

Future lines of inquiry for research in modelling, arising from the foregoing chapters, include more research with experienced modellers, the impact of teachers positioning themselves as modellers, strategic interventions by teachers during modelling, subcompetencies, anticipatory metacognition, and verification and validation.

Students in the study by Ortega et al. had no previous modelling experience, and other than in Germany (i.e. in the work by Hankeln et al. and Stender) this was 
typical. It is clear we need more research with students experienced in modelling as they engage with modelling tasks. Of course, this is not possible if curricula and or teachers do not value modelling and hence students are not engaged in mathematical modelling regularly.

One continuing line of inquiry should focus on the impact of teachers solving modelling tasks themselves before implementing these. Concurrent with undertaking this modelling, teachers must consider what blockages, difficulties, and challenges (Stillman et al. 2010) students might face when solving the task themselves. Interventions can be planned specific to the task, particularly following Stender, those intended to keep the student modellers doing all or most of the modelling and mathematical work. Following Vygotsky (1978), the interventions should relate to the Zone of Proximal Development of the task solver(s) and be strategic. In the first instance, if the intention is, as described by Blum and Borromeo Ferri (2009), to minimise teacher input and maximise student independence, teachers should consider strategic interventions "which give hints to students on a meta-level" (p. 52). This would include teacher responses such as: Can you imagine the situation? What is your aim? What else do you need to know? What does this (interim) result mean in terms of the real situation?

The work of Hankeln et al. regarding the possibilities of measuring individual sub-competencies should certainly be extended by themselves and other researchers to include non-geometric modelling situations and other grade levels of students. It would be beneficial to see studies of these same students engaged in complete modelling tasks as well.

Research is clearly needed with respect to teaching and learning approaches focused on issues related to students' mathematising successfully with both novice and experienced modellers. In 2010, Niss proposed the construct 'implemented anticipation' theorising as to the cognitive and metacognitive processes whereby student modellers foreshadow what might be useful mathematically in progressing a given problem, making decisions and implementing actions to bring what was anticipated to fruition. This is central to students being able to model (Stillman et al. 2015).

Subsequently, Stillman and Brown (2012) have found evidence of two aspects of anticipated implementation from classroom data. Furthermore, unsuccessful attempts at mathematisations were related to student's inability to use relevant mathematical knowledge in the modelling context rather than lack of mathematical knowledge, an application-oriented view of mathematics or persistence. In a following analysis modelling attempts when students were participating in an extra-curricular modelling event, Stillman and Brown (2014) found evidence of further aspects of implemented anticipation and that, again, unsuccessful modelling attempts could be explained using Niss' enablers of successful mathematisation. They suggest deliberately scaffolding the process of implemented anticipation as a "means of gaining a resolution of the long-standing issues of problem formulation and specification and their successful mathematisation" (Stillman et al. 2015). There is now a current research project investigating this further (see Geiger et al. 2018) with Year 10-11 students. This is most definitely a fruitful line of inquiry for others as well. 
Finally, verification and validation should be considered as an important line of inquiry for future research. Clearly, both are important in modelling, but challenging to implement, teach, and research. They also need to be clearly defined (see Czocher et al. 2018). This is not currently the case, as the terms are often used without definition or interchangeably. Further work along this line of inquiry is recommended.

\subsection{Conclusion}

In conclusion, this book has indeed presented a broad spectrum of valuable research in the field of mathematical modelling and applications in education through extended contributions by a small selection of presenters at ICME-13 in Topic Study Group 21: Mathematical Applications and Modelling in the Teaching and Learning of Mathematics. Issues related to mathematical applications and modelling in the teaching and learning of mathematics have continued to grow in interest from previous International Congresses on Mathematical Education. This is a very broad field both in terms of educational level range, from elementary school to tertiary education, and from the perspective of mathematical content and processes involved. The Topic Study Group thus attracted and catered for a breadth of participants through the plenaries and individual talks which addressed several theoretical issues and/or reported on diverse empirical studies. To unify this diversity, 15 authors or groups of authors were selected by the editors of this book and invited to start with their presentation and extend into a chapter but to link to the overarching theme of Lines of Inquiry in Mathematical Modelling Research in Education as had been elaborated and exemplified in the opening plenary by Stillman. Twelve chapters remained after the extensive review process.

The chapters covered a wide variety of educational levels from elementary and primary school students (Fulton et al., Zubi et al.) to secondary (Blomhøj, Hankeln et al., Ortega et al.), and tertiary students (Araújo, Caron, Czocher) as well as preservice and in-service development of their teachers (Blomhøj, Fulton et al., Shahbari and Tabach, Stender). Research on the teaching and learning of modelling provides a theoretical basis (e.g. conceptualisation of modelling competencies: Hankeln et al.) for the design and investigation of many different ways of implementing and organizing mathematical modelling in classrooms across these levels with the aim of developing student modelling competencies and, or, to support student learning of mathematics. The latter purpose is also informed by more general research in mathematics education (e.g. learning difficulties in conceptual and procedural development or learning trajectories for particular mathematical concepts).

The chapters in this book contribute to several lines of inquiry in researching or theorising with respect to teaching, learning, and assessing of modelling. Caron explored the approaches of mathematicians, mathematics teachers, and mathematics educators to solving complex dynamical systems (e.g. ecological systems) with a view to introducing such systems in school and university mathematics programs. Czocher analysed solutions of secondary and tertiary students to compare their solu- 
tions with that intended by the task setter. She found students were reluctant to simplify the situation as they saw this as creating a less authentic problem, not realising this is a critical component of task solving. She argues strongly that solutions other than the solution intended by the task setter in providing opportunities to address curriculum objectives, or those using mathematics not matching the curriculum being taught, must not be considered incorrect. Acknowledging the challenge of implementing modelling tasks at primary school, Fulton et al. investigated how this promoted meaningful task development by teachers and meaningful mathematical discourse by students. Hankeln et al. designed test items (multiple choice and short answer) for grade 9 geometric modelling ideas and showed these can be used to separately assess the modelling sub-competencies of simplifying, mathematising, interpreting, and validating. Ortega et al. explored how the available digital tools influenced grade 11 students' mathematisations when solving two functions-based tasks modelling physical phenomenon taking the stance of modelling as vehicle to enhance understanding about functions. Shahbari and Tabach investigated the impact of pre- and in-service teachers' engagement with modelling tasks themselves on their capacity to notice the complexity of modelling occurring when observing students engaged in modelling activity. Zubi et al. explored how a focus on development of modelling competencies by low achieving students led to improved mathematical understanding outside that focused on in the modelling tasks. This increase in mathematical understanding was, at least in part, a result of the changed expectations the young learners developed as active participants in the learning process.

In many cases researcher and pedagogical practice take place concurrently particularly if the researcher is also the teacher in the research study. Araújo's chapter addresses the dual role of researcher and educator in this setting from a socio-critical perspective in order to present her initial steps towards a framework for a dialectical relationship between pedagogical practice and research. Although clearly of application in mathematics education and educational research more generally, such a framework is particularly pertinent to mathematical modelling educational research given that mathematical modelling strongly depends on the situation of the learner which is not always the case in other parts of mathematics education. Other chapters addressed more general issues that inform the teaching and learning of mathematics through mathematical applications and modelling such as meanings of key terms such as context, task context, and real-world used by researchers in journal publications (Brown), and intervention strategies when managing modelling by others (Stender). Blomh $\varnothing j$ argues that to ensure modelling and applications are fully integrated into secondary mathematics classrooms, modelling must be seen and understood as a didactical means for supporting students' learning of mathematics not just to develop students' modelling competency. In order to do this he makes the case that there is a need for the development of tools that allow teachers to make better use of theories of learning of mathematical concepts and develop the pedagogical foresight to view modelling activities in this way.

Most lines of inquiry explored in the research represented here need further research as has been discussed in this chapter. Other major areas, not the subject of chapters in the book, include metacognition and modelling, affect and modelling, 
and the relationship of mathematical literacy to modelling. Each of these should be the subject of future research lines of inquiry.

\section{References}

Blomhøj, M., \& Højgaard Jensen, T. (2007). What's all the fuss about competencies? In W. Blum, P. L. Galbraith, H.-W. Henn, \& M. Niss (Eds.), Modelling and applications in mathematics education: The 14th ICMI study (pp. 45-256). New York: Springer.

Blum, W. (2015). Quality teaching of mathematical modelling: What do we know, what can we do? In. S. J. Cho (Ed.), Proceedings of the ICME12 (pp. 73-96). New York: Springer.

Blum, W., \& Borromeo Ferri, R. (2009). Mathematical modelling: Can it be taught and learnt? Journal of Mathematical Modelling and Application, 1(1), 45-58.

Blum, W., Galbraith, P., Henn, H.-W., \& Niss, M. (2007). Preface. In W. Blum, P. Galbraith, H.-W. Henn, \& M. Niss (Eds.), Modelling and applications in mathematics education: The 14th ICMI study (pp. xi-xiv). New York: Springer.

Blum, W., \& Leiß, D. (2005). "Filling Up"-the problem of independence-preserving teacher interventions in lessons with demanding modelling tasks. In M. Bosch (Ed.), Proceedings CERME4 (pp. 1623-1633). Girona, Spain: ERME.

Brown, J. (2015a). Complexities of digital technology use and the teaching and learning of function. Computers \& Education, 87, 112-122.

Brown, J. P. (2015b). Visualisation tactics for solving real world tasks. In G. A. Stillman, W. Blum, \& M. S. Biembengut (Eds.), Mathematical modelling in education research and practice (pp. 431-442). Cham, Switzerland: Springer.

Brown, J. P., \& Stillman, G. (2014). Affordances: Ten years on. In J. Anderson, M. Cavanagh, \& A. Prescott (Eds.), Proceedings MERGA37 (pp. 111-118). Sydney: MERGA.

Caron, F. (2019). Approaches to investigating complex dynamical systems. In G. A. Stillman \& J. P. Brown (Eds.), Lines of inquiry in mathematical modelling research in education (pp. 83-103). Cham: Springer.

Cuoco, A., Goldenberg, E. P., \& Mark, J. (1996). Habits of mind: An organizing principle for a mathematics curriculum. Journal of Mathematical Behavior, 14(4), 375-402.

Czocher, J., Stillman, G., \& Brown, J. (2018). Verification and validation: What do we mean? Proceedings MERGA41 (pp. 250-257). Auckland, NZ: MERGA.

Davis, P. J. (1991). Applied mathematics as a social instrument. In M. Niss, W. Blum, \& I. Huntley (Eds.), Teaching of mathematical modelling and applications (pp. 1-9). New York: Horwood.

Doerr, H. M., Ärlebäck, J. B., \& Misfledt, M. (2017). Representations of modelling in mathematics education. In G. A. Stillman, W. Blum, \& G. Kaiser (Eds.), Mathematical modelling and applications (pp. 71-81). Cham: Springer.

Frejd, P., \& Ärlebäck, J. B. (2017). Initial results of an intervention using a mobile game app to simulate a pandemic outbreak. In G. A. Stillman, W. Blum, \& G. Kaiser (Eds.), Mathematical modelling and applications: Crossing and researching boundaries in mathematics education (pp. 517-527). Cham: Springer.

Fulton, E. W., Wickstrom, M. H., Carlson, M. A., \& Burroughs, E. A. (2019). Teachers as learners: Engaging communities of learners in mathematical modelling through professional development. In G. A. Stillman \& J. P. Brown (Eds.), Lines of inquiry in mathematical modelling research in education (pp. 125-142). Cham: Springer.

Galbraith, P. (2007). Beyond the low hanging fruit. In W. Blum, P. Galbraith, M. Niss, \& H.-W. Henn (Eds.), Modelling and applications in mathematics education: The 14th ICMI study (pp. 79-88). New York: Springer. 
Galbraith, P., Stillman, G., Brown, J., \& Edwards, I. (2007). Facilitating middle secondary modelling competencies. In C. Haines, P. Galbraith, W. Blum, \& S. Khan (Eds.), Mathematical modelling: Education, engineering and economics (pp. 130-140). Chichester, UK: Horwood.

Galbraith, P. L., Stillman, G., \& Brown, J. (2010). Turning ideas into modeling problems. In R. Lesh, et al. (Eds.), Modeling students' mathematical modeling competencies (pp. 133-144). New York: Springer.

Geiger, V., Stillman, G., Brown, J., Galbraith, P., \& Niss, M. (2018). Using mathematics to solve real world problems: The role of enablers. Mathematics Education Research Journal, 30(1), 7-19.

Gibson, J. (1979). The ecological approach to visual perception. Boston, MA: Houghton Mifflin.

Greefrath, G., \& Siller, S. (2017). Modelling and simulation with the help of digital tools. In G. A. Stillman, W. Blum, \& G. Kaiser (Eds.), Mathematical modelling and applications: Crossing and researching boundaries in mathematics education (pp. 529-539). Cham: Springer.

Hankeln, C., Adamek, C., \& Greefrath, G. (2019). Assessing sub-competencies of mathematical modelling-development of a new test instrument. In G. A. Stillman \& J. P. Brown (Eds.), Lines of inquiry in mathematical modelling research in education (pp. 143-160). Cham: Springer.

Ikeda, T. (2015). Mathematical modelling in Japan. In N. H. Lee \& K. E. D. Ng (Eds.), Mathematical modelling from theory to practice (pp. 83-96). Singapore: World Scientific.

Jacobson, M. J., \& Wilensky, U. (2006). Complex systems in education: Scientific and educational importance and implications for the learning sciences. Journal of the Learning Sciences, 15(1), $11-34$.

Julie, C. (2002). Making relevance relevant in mathematics teacher education. Proceedings ICTM2. Hoboken, NJ: Wiley [CD-ROM].

Julie, C., \& Mudaly, V. (2007). Mathematical modelling of social issues in school mathematics in South Africa. In W. Blum, P. L. Galbraith, H.-W. Henn, \& M. Niss (Eds.), Modelling and applications in mathematics education (pp. 503-510). New York: Springer.

Kaiser, G., \& Brand, S. (2015). Modelling competencies: Past development and further perspectives. In G. A. Stillman, W. Blum, \& M. S. Biembengut (Eds.), Mathematical modelling in education research and practice (pp. 129-149). Cham: Springer.

Maaß, K. (2006). What are modelling competencies? ZDM Mathematics Education, 38(2), 113-142.

Maaß, K. (2016). Mathematical modelling in professional development-Traditions in Germany. Talk given at Thematic Afternoon: Mathematical Modelling in German Speaking Countries on 27 July, 2016, at ICME 13 in Hamburg, Germany.

Meyer, W. J. (1984). Concepts of mathematical modeling. New York: McGraw-Hill.

Niss, M. (2015). Prescriptive modelling — challenges and opportunities. In G. A. Stillman, W. Blum, $\&$ M. S. Biembengut (Eds.), Mathematical modelling in education research and practice: $\mathrm{Cul}$ tural, social and cognitive influences (pp. 67-79). Cham: Springer.

Ortega, M., Puig, L., \& Albarracín, L. (2019). The influence of technology on the mathematical modelling of physical phenomena. In G. A. Stillman \& J. P. Brown (Eds.), Lines of inquiry in mathematical modelling research in education (pp. 161-177). Cham: Springer.

Roache, P. J. (1998). Verification and validation in computational science and engineering. Albuquerque, NM: Hermosa.

Stender, P. (2019). Heuristic strategies as a toolbox in complex modelling problems. In G. A. Stillman \& J. P. Brown (Eds.), Lines of inquiry in mathematical modelling research in education (pp. 197-212). Cham: Springer.

Stillman, G., \& Brown, J. P. (2012). Empirical evidence for Niss' implemented anticipation in mathematising realistic situations. In J. Dindyal, L. P. Cheng, \& S. F. Ng (Eds.), Proceedings MERGA 35 (pp. 682-689). Singapore: MERGA.

Stillman, G., \& Brown, J. (2014). Evidence of "implemented anticipation" in mathematising by beginning modellers. Mathematics Education Research Journal, 26(4), 763-789.

Stillman G., Brown J., Galbraith P. (2010). Identifying challenges within transition phases of mathematical modeling activities at Year 9. In R. Lesh, P. Galbraith, C. Haines, \& A. Hurford (Eds.), Modeling students' mathematical modeling competencies. Dordrecht, The Netherlands: Springer. 
Stillman, G., Brown, J., \& Geiger, V. (2015). Facilitating mathematisation in modelling by beginning modellers in secondary school. In G. A. Stillman, W. Blum, \& M. S. Biembengut (Eds.), Mathematical modelling in education research and practice: Cultural, social and cognitive influences (pp. 93-104). Cham: Springer.

Stillman, G., Cheung, K. C., Mason, R., Sheffield, L., Sriraman, B., \& Ueno, K. (2009). Challenging mathematics: Classroom practices. In E. Barbeau \& P. Taylor (Eds.), Challenging mathematics in and beyond the classroom (pp. 243-283). Boston, MA: Springer.

Stillman, G. A. (2019). State of the art on modelling in mathematics education-Lines of inquiry. In G. A. Stillman \& J. P. Brown (Eds.), Lines of inquiry in mathematical modelling research in education (pp. 1-20). Cham: Springer.

Tan, L. S., \& Ang, K. C. (2013). Pre-service secondary school teachers' knowledge in mathematical modelling-A case study. In G. A. Stillman, G. Kaiser, W. Blum, \& J. P. Brown (Eds.), Teaching mathematical modelling: Connecting to research and practice (pp. 373-383). Dordrecht: Springer.

Vygotsky, L. S. (1978). Interaction between learning and development. In M. Cole, V. John-Steiner, S. Scribner, \& E. Souberman (Eds.), Mind and society: The development of higher psychological processes (pp. 79-91). Cambridge, MA: Harvard University Press.

Open Access This chapter is licensed under the terms of the Creative Commons Attribution 4.0 International License (http://creativecommons.org/licenses/by/4.0/), which permits use, sharing, adaptation, distribution and reproduction in any medium or format, as long as you give appropriate credit to the original author(s) and the source, provide a link to the Creative Commons license and indicate if changes were made.

The images or other third party material in this chapter are included in the chapter's Creative Commons license, unless indicated otherwise in a credit line to the material. If material is not included in the chapter's Creative Commons license and your intended use is not permitted by statutory regulation or exceeds the permitted use, you will need to obtain permission directly from the copyright holder.

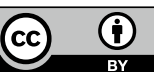

